Article

\title{
Detection of Cyanotoxins in Algae Dietary Supplements
}

\author{
Audrey Roy-Lachapelle ${ }^{1}$, Morgan Solliec ${ }^{1}$, Maryse F. Bouchard ${ }^{2}$ and Sébastien Sauvé ${ }^{1, *}$ \\ 1 Department of Chemistry, Université de Montréal, Montréal, QC H3T 1J4, Canada; \\ a.roy.lachapelle@umontreal.ca (A.R.-L.); morgan.solliec@umontreal.ca (M.S.) \\ 2 Department of Environmental and Occupational Health, Université de Montréal, \\ Montréal, QC H3T 1A8, Canada; maryse.bouchard@umontreal.ca \\ * Correspondence: sebastien.sauve@umontreal.ca; Tel.: +514-343-6749, Fax: +514-343-7586
}

Academic Editor: Amparo Alfonso

Received: 6 December 2016; Accepted: 21 February 2017; Published: 25 February 2017

\begin{abstract}
Algae dietary supplements are marketed worldwide as natural health products. Although their proprieties have been claimed as beneficial to improve overall health, there have been several previous reports of contamination by cyanotoxins. These products generally contain non-toxic cyanobacteria, but the methods of cultivation in natural waters without appropriate quality controls allow contamination by toxin producer species present in the natural environment. In this study, we investigated the presence of total microcystins, seven individual microcystins (RR, YR, LR, LA, LY, LW, LF), anatoxin-a, dihydroanatoxin-a, epoxyanatoxin-a, cylindrospermopsin, saxitoxin, and $\beta$-methylamino-L-alanine in 18 different commercially available products containing Spirulina or Aphanizomenon flos-aquae. Total microcystins analysis was accomplished using a Lemieux oxidation and a chemical derivatization using dansyl chloride was needed for the simultaneous analysis of cylindrospermopsin, saxitoxin, and $\beta$-methylamino-L-alanine. Moreover, the use of laser diode thermal desorption (LDTD) and ultra-high performance liquid chromatography (UHPLC) both coupled to high resolution mass spectrometry (HRMS) enabled high performance detection and quantitation. Out of the 18 products analyzed, 8 contained some cyanotoxins at levels exceeding the tolerable daily intake values. The presence of cyanotoxins in these algal dietary supplements reinforces the need for a better quality control as well as consumer's awareness on the potential risks associated with the consumption of these supplements.
\end{abstract}

Keywords: cyanotoxins; cyanobacteria; dietary supplements; LC-HRMS; LDTD; microcystins; anatoxin-a; cylindrospermopsin; BMAA; saxitoxin

\section{Introduction}

Cyanobacteria (CB), formally called blue-green algae, are omnipresent in natural water sources and cause increased concern for public health [1]. Although they are mostly innocuous, a significant proportion of cyanobacterial species are harmful due to toxin production [2]. Cyanotoxins have several modes of action including: hepatotoxicity, affecting mainly the liver; neurotoxicity, acting on the nerve cells; cytotoxicity, affecting the cells and potentially carcinogenic; and dermatotoxicity, acting as irritant [3]. The production of massive cyanobacterial blooms can be caused by eutrophic conditions in the presence of heat, light, shallow waters, and nutrients [1,3]. Moreover, intense agriculture activities, and more recently, climate changes have been the principal triggers of massive cyanobacterial blooms $[4,5]$. The production of cyanobacteria, as well as their cyanotoxins, is almost impossible to predict precisely [6]. The nature of the producing cells and toxins, the localization of proliferation, and the duration of the bloom at a specific location are hard to characterize, which makes their management difficult. 
CB have been commercialized as dietary supplements and recently gained popularity for their alleged beneficial effects on health for adults and children, including an increase in energy, better mood, antioxidant proprieties, and anti-cancer effects [7-9]. Our investigation included two types of CB supplements: Spirulina, which is now recognized by two species named Arthrospira platensis and Arthrospira maxima, the latter being found worldwide and are considered innocuous [10]; and non-toxic Aphanizomenon flos-aquae is also used from blooms to produce food supplements and has been primarily harvested from Upper Klamath Lake in Oregon, USA. However, toxic strains of A. flos-aquae may be found occasionally in some supplements, and they have been reported to produce paralytic shellfish poisons and anatoxin-a [11]. Moreover, despite some quality control as described by Carmichael et al. [10], other CB species can accidentally contaminate the products since the production is made in the natural environment. Indeed, the presence of microcystins and alkaloid cyanotoxins producers have been found in supplements [10,12-14]. Yet, most dietary supplements suffer from less strict quality controls since they are categorized as foodstuff products and not as pharmaceuticals [15]. Moreover, they are marketed internationally, sold over-the-counter, and easily accessible via the Internet without any guarantee of proper quality controls. Previous studies showed the presence of microcystins at concentration levels exceeding the proposed World Health Organization's (WHO) tolerable daily intake (TDI) of $0.04 \mu \mathrm{g} \cdot \mathrm{kg}^{-1}$ body weight for an adult [16-20]. This TDI is an estimate of the amount of microcystins that can be ingested daily over a lifetime without appreciable health risk. Anatoxin-a and its congeners have been reported in different brands containing both Spirulina and A. flos-aquae [13,17]. Moreover, some strains of A. flos-aquae are known to produce saxitoxins and $\beta$-methylamino-L-alanine, the presence of the latter having been confirmed in $\mathrm{CB}$ dietary supplements [21-26].

In this paper, we aim to analyze different brands of $C B$ dietary supplements to screen for the presence of different cyanotoxins: microcystins (MCs), anatoxin-a (ANA-a), cylindrospermopsin $(\mathrm{CYN})$, saxitoxin (STX), and $\beta$-methylamino-L-alanine (BMAA). The use of different analytical strategies coupled with high resolution mass spectrometry (HRMS) detection allows us to confirm the presence of different cyanotoxins which could not be analysed in a single analytical run due to their structure specificity. The structural identification and compound profiles were obtained using the Q-Exactive orbital ion trap, which enabled selective detection for all targeted compounds, both with and without the use of certified standard materials. For this purpose, we used different analytical approaches previously developed in our laboratory including laser diode thermal desorption (LDTD) for a fast screening of total MCs and ANA-a (approximately $10 \mathrm{~s}$ per sample) while eliminating a chromatographic separation step [27-29]. More specifically, Lemieux oxidation using potassium permanganate and sodium periodate allowed the recovery of the 2-methyl-3-methoxy-4-phenylbutyric acid (MMPB) moiety common to all MCs which includes over 100 known congeners [30]. Samples were also submitted to ultra-high performance liquid chromatography-heated electrospray (UHPLC-HESI) coupled to HRMS, which were previously developed and ultimately adapted for this project [31]. The MC congeners present in the samples were then identified and quantified and results were compared with total MCs quantification results. Transformation products of ANA-a were qualitatively searched including dihydroanatoxin-a (DH-ANA-a) and epoxyanatoxin-a (E-ANA-a) and they were semi-quantified using ANA-a as a reference standard [32]. Finally, the analysis of CYN, STX, and BMAA was possible with a derivatization step using dansyl chloride (DNS) which was also previously developed [33].

Upon long term consumption, the presence of undesirable and harmful toxins in dietary supplements would lead to public health concerns as they are widely available, labeled as safe products, and even promoted as beneficial for health. By screening a large variety of cyanotoxins in these supplements, we aim to assess their toxic potential. 


\section{Results and Discussion}

\subsection{Multi-Toxins Analysis and Validation}

Different analytical approaches have been used to determine the presence of several cyanotoxins in Spirulina and A. flos-aquae dietary supplements available worldwide in stores or via the Internet [11-13,17,34-36]. Analytical methods for the analysis of cyanotoxins, until now, cannot encompass the presence of a multitude of congeners and their diversity in terms of physicochemical properties. Using previously developed analytical methods for different cyanotoxin families, we were able to analyse total MCs via the MMPB moiety and compare results to multi MCs detection using seven standards. We were also able to compare results using ultra-fast detection of ANA-a using the LDTD-APCI-HRMS to UHPLC-HESI-HRMS method. The detection of CYN, STX, and BMAA was possible using DNS derivatization prior to UHPLC-HESI-HRMS analysis. Finally, transformation products of ANA-a were evaluated and confirmed using HRMS detection and were semi-quantified. To evaluate the validation parameters from the different analytical methods, Chlorella based dietary supplement products were used as relevant matrix material, thus as method blanks. Indeed, Chlorella is used and sold similarly as other CB dietary supplements, only, instead of being a cyanobacterium, this genus is a unicellular green algae. Nevertheless, matrix blanks were evaluated in every analysis to ensure the absence of false positives.

\subsubsection{Evaluation of Extraction Methods}

Different extraction methods were employed depending on the targeted cyanotoxins and the analytical methods. The extraction recoveries (Table 1) and matrix effects (Table S1) were evaluated at two concentration levels for all target cyanotoxins in triplicate at two levels of concentrations. The extraction recovery of total MCs was evaluated using a Lemieux oxidation protocol previously developed and validated in our laboratory and other research groups $[28,29,37,38]$. The extraction recoveries, including oxidation reaction and SPE extraction, were $79 \%$ and $85 \%$ and signal recoveries from matrix effects were $85 \%$ and $87 \%$. The analysis of ANA-a using the LDTD-APCI-HRMS method resulted in extraction recoveries of $95 \%$ and $92 \%$ and signal recoveries from matrix effects of $90 \%$ and $92 \%$. For the analysis of the different MCs and ANA-a, results showed extraction recoveries between $85 \%$ and $96 \%$ and signal recovery from matrix effects between $91 \%$ and $112 \%$, respectively. Finally, for the derivatization and SPE extraction steps combined of CYN, STX, and BMAA, extraction recoveries ranged from $83 \%$ to $97 \%$ and signal recoveries from matrix effect ranged from $94 \%$ to $109 \%$. Globally, the different extraction steps showed acceptable recoveries while eliminating substantial background signals which could otherwise contribute to enhance matrix effects. It was acceptable with no significant signal enhancement or loss. The only exceptions came from the analysis of total MCs via the MMPB moiety. Lower extraction recoveries were obtained due to the complexity of the extraction steps necessary for obtaining the MMPB moiety, but compared to previous studies, these values are deemed acceptable [37,38]. Also, slight signal suppression was observed, which can be due to the presence of residual salts from the oxidation reagents, which can interfere with the LDTD desorption [28].

\subsubsection{Methods Validation}

Method validation was done by evaluating linearity, precision (intraday and interday), accuracy, method detection (MDLs) and quantification limits (MQLs) in Chlorella samples used as matrix blanks (Table 1). The calibration curves of the spiked cyanotoxins showed good linearity with $R^{2} \geq 0.9985$ using the corresponding internal standards. The precision and accuracy (\% bias) of the methods were determined at two concentration levels by analysing replicates of spiked blank matrix samples in triplicate. The precision and the accuracy for all analytes were deemed suitable, ranging from $1 \%$ to 15\% and between 2 and 12, respectively. The MDLs and MQLs values ranged from 0.01 to $0.3 \mu \mathrm{g} \cdot \mathrm{g}^{-1}$ and 0.03 to $0.8 \mu \mathrm{g} \cdot \mathrm{g}^{-1}$, respectively. The evaluated MDLs and MQLs of the present developed method 
were comparable to previous developed methods for the analysis of cyanotoxins in freeze-dried cyanobacterial cells [39,40]. In comparison, UHPLC-HESI-HRMS methods offered better results in terms of MDLs and MQLs, which was expected. However, the results obtained for total MCs via MMPB and ANA-a were substantially lower than provisional TDI guidelines being approximately $2.4 \mu \mathrm{g}$ of MC-LReq and $6 \mu \mathrm{g}$ daily for an adult weighing $60 \mathrm{~kg}$ compared to the MDL being 0.2 and $0.3 \mu \mathrm{g} \cdot \mathrm{g}^{-1}$, respectively $[20,41]$. Considering this, the LDTD-APCI-HRMS analytical apparatus given by previous methods and this paper can be a great tool for faster screening of the target cyanotoxins as demonstrated.

Table 1. Method validation parameters including accuracy and precision determined at two different concentrations levels and recovery with standard deviation (STD, $n=3)$.

\begin{tabular}{|c|c|c|c|c|c|c|c|c|c|c|c|c|c|}
\hline \multicolumn{2}{|c|}{ Compounds ${ }^{a}$} & \multicolumn{2}{|c|}{$\begin{array}{c}\text { Accuracy } \\
\text { (RE \%) }\end{array}$} & \multicolumn{2}{|c|}{$\begin{array}{l}\text { Intraday } \\
\text { (RSD \%) }\end{array}$} & \multicolumn{2}{|c|}{$\begin{array}{l}\text { Interday } \\
\text { (RSD \%) }\end{array}$} & \multicolumn{2}{|c|}{ Recovery (\%) } & \multirow[t]{2}{*}{$R^{2}$} & \multirow[t]{2}{*}{$\begin{array}{c}\text { Linearity } \\
\text { Range }\left(\mu \mathrm{g} \cdot \mathrm{g}^{-1}\right)\end{array}$} & \multirow{2}{*}{$\begin{array}{c}\text { MDL } \\
\left(\mu \mathrm{g} \cdot \mathrm{g}^{-1}\right)\end{array}$} & \multirow{2}{*}{$\begin{array}{c}\mathrm{MQL} \\
\left(\mu \mathrm{g} \cdot \mathrm{g}^{-1}\right)\end{array}$} \\
\hline & & $\mathbf{L}$ & $\mathbf{H}$ & $\mathbf{L}$ & $\mathbf{H}$ & L & $\mathbf{H}$ & $\mathbf{L}$ & $\mathbf{H}$ & & & & \\
\hline \multirow{2}{*}{1} & $\mathrm{MMPB}^{\mathrm{b}, \mathrm{c}}$ & 8 & 6 & 7 & 9 & 12 & 12 & $79(9)$ & $85(10)$ & 0.9988 & $0.6-20$ & 0.2 & 0.6 \\
\hline & ANA-a ${ }^{b}$ & 6 & 5 & 6 & 7 & 11 & 13 & $95(7)$ & $92(8)$ & 0.9987 & $0.8-20$ & 0.3 & 0.8 \\
\hline \multirow{8}{*}{2} & ANA-a & 9 & 7 & 5 & 5 & 8 & 9 & $89(7)$ & $90(8)$ & 0.9995 & $0.1-20$ & 0.04 & 0.1 \\
\hline & MC-RR & 7 & 8 & 7 & 3 & 11 & 8 & $86(9)$ & $89(8)$ & 0.9993 & $0.03-20$ & 0.01 & 0.03 \\
\hline & MC-YR & 8 & 4 & 5 & 2 & 12 & 9 & $85(7)$ & $90(6)$ & 0.9992 & $0.07-20$ & 0.02 & 0.07 \\
\hline & MC-LR & 6 & 3 & 7 & 6 & 9 & 7 & $91(10)$ & 95 (10) & 0.9995 & $0.06-20$ & 0.02 & 0.06 \\
\hline & MC-LA & 6 & 4 & 5 & 1 & 9 & 11 & $92(7)$ & 91 (9) & 0.9990 & $0.03-20$ & 0.01 & 0.03 \\
\hline & MC-LY & 7 & 6 & 8 & 5 & 7 & 9 & $87(8)$ & $92(8)$ & 0.9995 & $0.1-20$ & 0.03 & 0.1 \\
\hline & MC-LW & 10 & 7 & 9 & 4 & 9 & 10 & $96(7)$ & $94(9)$ & 0.9993 & $0.05-20$ & 0.02 & 0.05 \\
\hline & MC-LF & 8 & 5 & 10 & 2 & 11 & 8 & $93(9)$ & $90(7)$ & 0.9992 & $0.1-20$ & 0.03 & 0.1 \\
\hline \multirow{3}{*}{3} & CYN & 11 & 10 & 11 & 9 & 15 & 12 & $88(10)$ & $85(7)$ & 0.9990 & $0.1-20$ & 0.04 & 0.1 \\
\hline & STX & 12 & 10 & 12 & 8 & 13 & 13 & $83(11)$ & $86(9)$ & 0.9989 & $0.3-20$ & 0.1 & 0.3 \\
\hline & BMAA & 8 & 7 & 8 & 8 & 10 & 12 & $97(6)$ & $94(5)$ & 0.9993 & $0.08-20$ & 0.02 & 0.08 \\
\hline
\end{tabular}

${ }^{a}$ Validation results are divided between the three methods. L (low concentration) and $\mathrm{H}$ (high concentrations) are respectively set as the follow: 1 and $10 \mu \mathrm{g} \cdot \mathrm{g}^{-1}(1), 0.1$ and $10 \mu \mathrm{g} \cdot \mathrm{g}^{-1}$ (2), and 0.5 and $10 \mu \mathrm{g} \cdot \mathrm{g}^{-1}$ (3). ${ }^{\mathrm{b}}$ Analysis using LDTD-APCI-HRMS detection. ${ }^{c}$ Results reported as total MCs equivalent.

\subsection{Toxins Quantification in CB Dietary Supplements}

From the $18 \mathrm{CB}$ dietary products tested, fourteen contained Spirulina and four contained A. flos-aquae. They were analysed on a mass basis (as $\mu \mathrm{g}$ of cyanotoxins per $\mathrm{g}$ of dry weighed CB) and results are presented in Table S2. Three brands out of the 14 Spirulina products contained amounts of total MCs varying between 0.25 and $0.84 \mu \mathrm{g} \cdot \mathrm{g}^{-1}$. In comparison, the concentrations obtained using the sum of individual MC standards varied between 0.01 and $0.63 \mu \mathrm{g} \cdot \mathrm{g}^{-1}$. As for the $A$. flos-aquae-based brands, amounts of total MCs were substantially higher with results varying between 0.8 and $8.2 \mu \mathrm{g} \cdot \mathrm{g}^{-1}$ using the Adda oxidation method. In comparison, by using the sums of MCs standards, the concentrations varied between 0.52 and $5.8 \mu \mathrm{g} \cdot \mathrm{g}^{-1}$. As seen in previous studies, there is a possibility of underestimation when total MC is not taken into account since only a limited number of MC variants are available as standards (approximately 10\%). In our case, the presence of unseen variants and congener isomers is probable considering the results obtained. Two methods were used to quantify ANA-a, the first using the LDTD-APCI-HRMS for faster screening and the second using UHPLC-HESI-HRMS to include the toxin in a multi-toxins analytical method. Results showed the presence of ANA-a in two A. flos-aquae CB dietary supplements. In one of these samples, similar amounts were detected using the two analytical methods, i.e., $0.44 \mu \mathrm{g} \cdot \mathrm{g}^{-1}$ of ANA-a using the LDTD-APCI-HRMS and $0.40 \mu \mathrm{g} \cdot \mathrm{g}^{-1}$ using the UHPLC-HESI-HRMS. In the other sample, only the second analytical method detected ANA-a, with an obtained amount of $0.15 \mu \mathrm{g} \cdot \mathrm{g}^{-1}$, which is explained by the MDL of the two different methods. An example to illustrate the LDTD peak shape of MMPB and ANA-a is presented in Figure 1 from brand \#17. Figure 2 illustrates the chromatographic separation of ANA-a and the individual MCs from brand \#15. Finally, CYN and STX were not detected in any samples, but two samples of $A$. flos-aquae contained BMAA with amounts of 0.04 
and $0.55 \mu \mathrm{g} \cdot \mathrm{g}^{-1}$. An example of the chromatographic separation is shown in Figure 3 from brand \#15 including a clear separation of BMAA and its isobaric isomer 2,3-diaminobutyric acid (DAB). Globally, Spirulina-based brands contained less cyanotoxins than A. flos-aquae based brands and this phenomenon was previously observed [42]. Normally, Spirulina does not have the capacity to produce cyanotoxins [10]. Moreover, their harvest requires specific conditions ( $\mathrm{pH} 9-10)$ which are not suitable for the efflorescence of a large number of CB [11]. However, it was previously found that Arthospira, a potential ANA-a producer, can appear in the harvest of Spirulina and can be missed during quality controls, due to their similar morphology [14,43]. The presence of other toxic CB such as Microcystis has also been documented [44]. As for A. flos-aquae, all our selected brands showed the presence of cyanotoxins, which is in concordance with many studies $[12,13,19]$. Such samples mostly contain MCs, but previous analysis showed that alkaloid cyanotoxins can also be found in A. flos-aquae culture, therefore in CB dietary supplements. BMAA was found in two samples containing A. flos-aquae. BMAA can cause neurodegeneration in animal models, and is suspected to be linked to neurodegenerative diseases $[45,46]$. Thus, its mere presence in a food supplement represents a potential concern for public health.

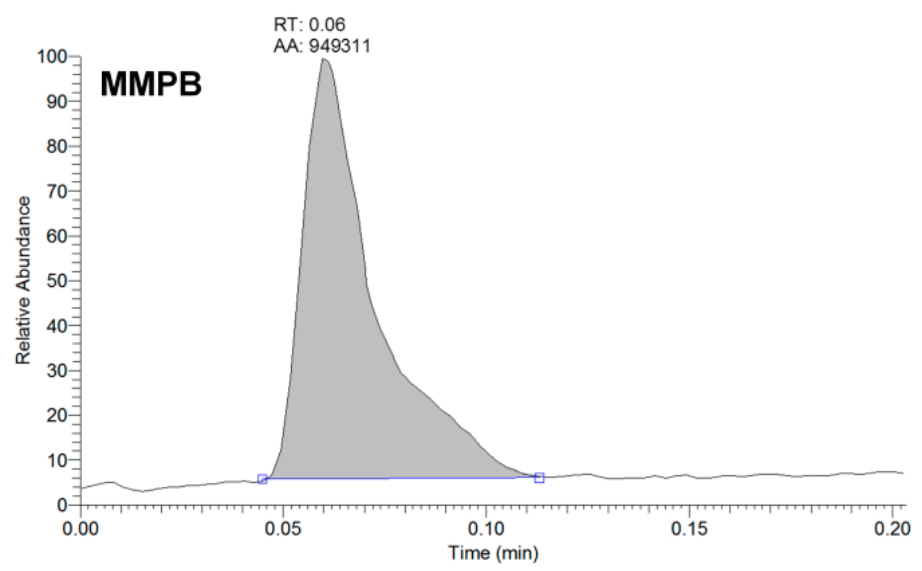

(a)

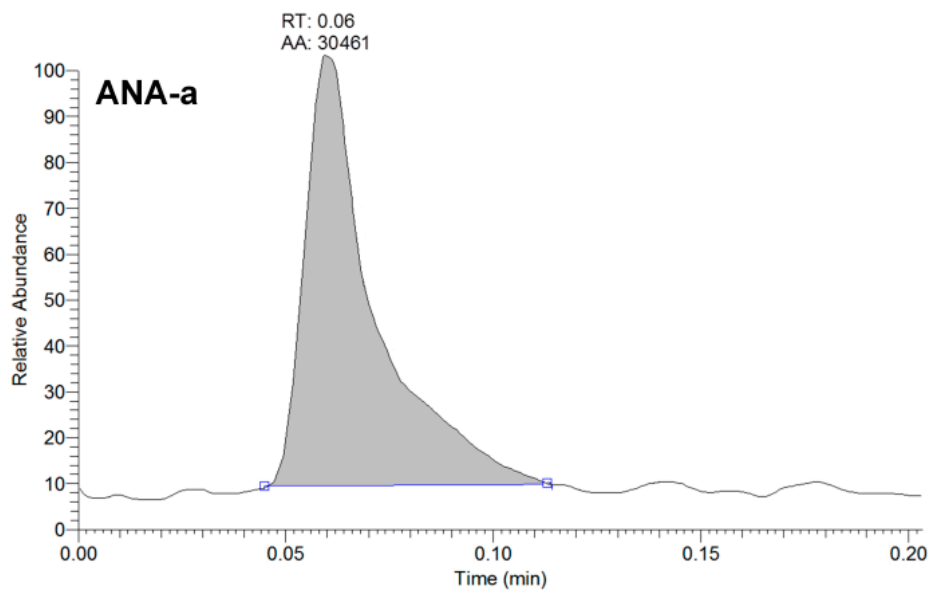

(b)

Figure 1. Example of peak shape from the analysis of brand \#17 using LDTD-APCI-HRMS detecting (a) MMPB for total microcystins analysis, and (b) anatoxin-a (ANA-a). The analytes are represented by the integrated peaks with corresponding retention times (RT) and area (AA). 

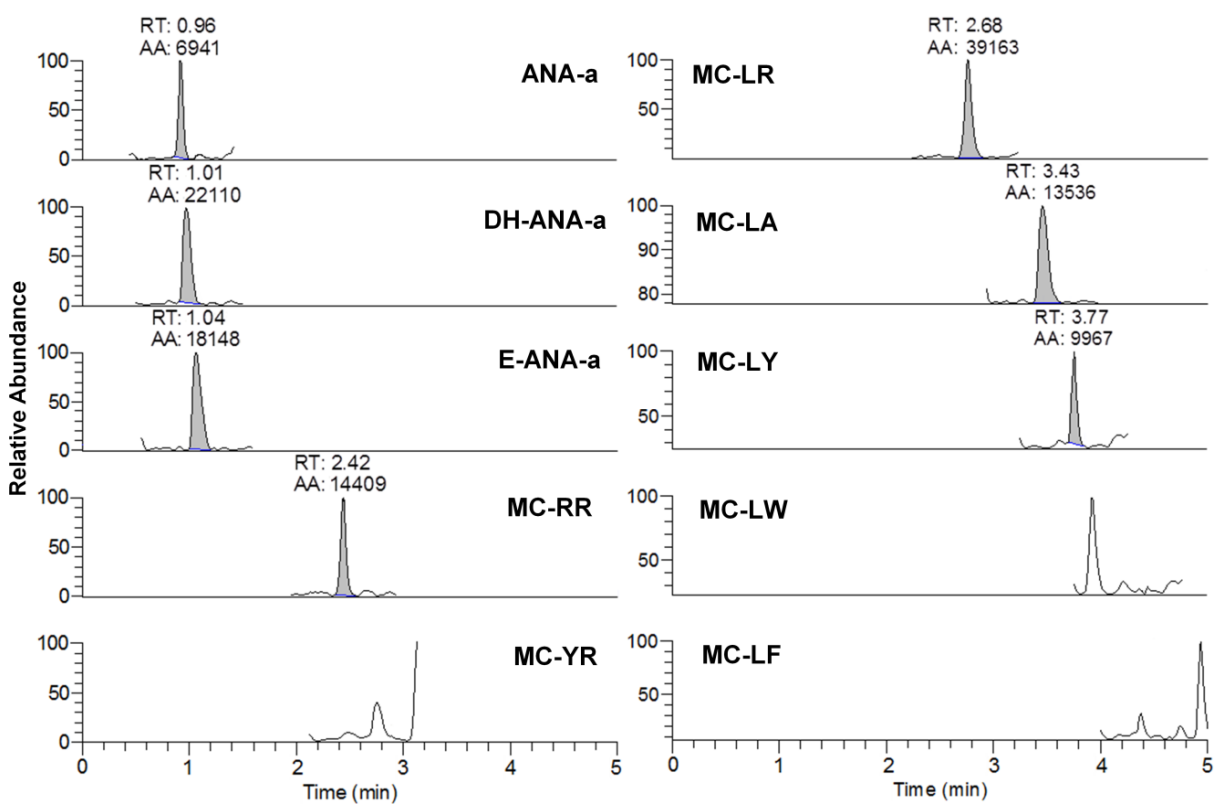

Figure 2. Example of chromatogram from the analysis of brand \#15 using DNS derivatization and UHPLC-HESI-HRMS analysis for anatoxin-a (ANA-a), dihydroanatoxin-a (DH-ANA-a), epoxyanatoxin-a (E-ANA-a), and seven microcystins (RR, YR, LR, LA, LY, LY, LW, and LF). The analytes are represented by the integrated peaks with corresponding retention times (RT) and area (AA).

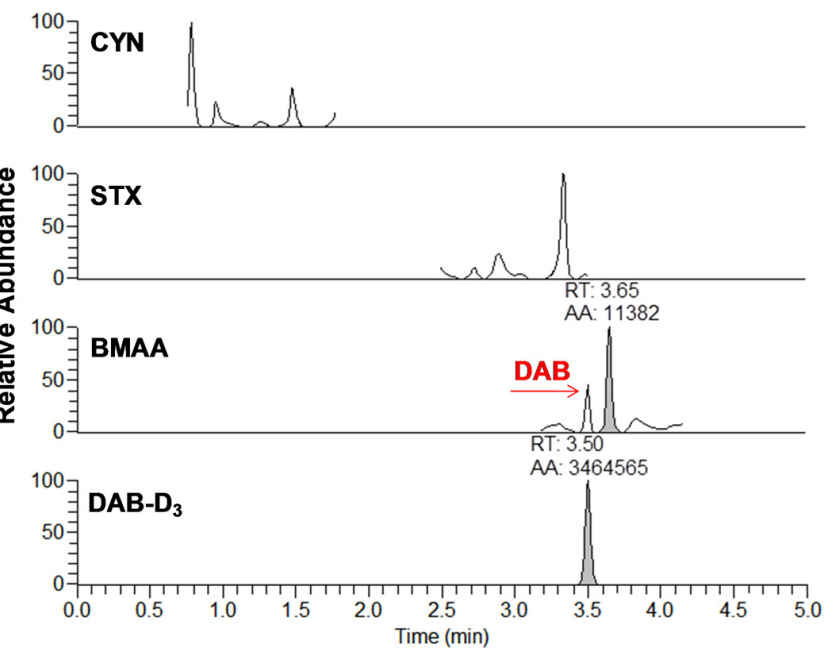

Figure 3. Example of chromatogram from the analysis of brand \#15 using DNS derivatization and UHPLC-HESI-HRMS analysis for cylindrospermopsin (CYN), saxitoxin (STX), $\beta$-methylaminoL-alanine (BMAA), and diaminobutyric acid- $\mathrm{D}_{3}\left(\mathrm{DAB}-\mathrm{D}_{3}\right)$. The analytes are represented by the integrated peaks with corresponding retention times (RT) and area (AA).

\subsection{Transformation Products ANA-a}

ANA-a is a labile compound which is easily transformed under natural conditions, including alkaline $\mathrm{pH}$ and UV light. However, it can be transformed into less toxic and more stable compounds, which includes DH-ANA-a and E-ANA-a. Their presence was monitored to assess the possibility of ANA-a production in a CB harvest, which can add a possible presence of toxic $C B$ in the cultures that would not be detectable in the products. Due to the lack of certified standards, these compounds were searched and confirmed using HRMS detection and they were semi-quantified using the ANA-a standard for calibration. DH-ANA-a was found in three samples at concentrations varying between 
0.34 and $7.2 \mu \mathrm{g} \cdot \mathrm{g}^{-1}$ and E-ANA-a was found in four samples at concentrations between 0.07 and $2.7 \mu \mathrm{g} \cdot \mathrm{g}^{-1}$. These concentrations, even if approximate, were substantially higher than concentrations obtained for ANA-a. Similarly to our results, Draisci et al. [17], found transformation products of ANA-a without finding the parent molecule. This suggested a potential health hazard associated with CB dietary supplement consumption. To ensure the identification of the compounds, comparisons of fragmentation patterns, which are shown in Figure 4, were done using the Mass Frontier ${ }^{\mathrm{TM}}$ software. The obtained results confirmed their structure identification, therefore supporting their presence in samples. For DH-ANA-a, the targeted product ions for identification were $\mathrm{m} / \mathrm{z} 168.1381>96.0396$, 133.1010, and 150.1275. For E-ANA-a, the product ions were $\mathrm{m} / \mathrm{z} 182.1178>98.0966,122.0964$, and 164.1068. These masses are in accordance with the results presented in previous studies which were obtained using reference standards and LC-MS/MS detection [16,47]. Moreover, to ensure proper identification, the structures were searched via the Mass Frontier ${ }^{\mathrm{TM}}$ software using their exact mass and are illustrated in Figure 4. Indeed, we found plausible structures for each of the masses used for identification with mass errors equal or below 3 ppm, thus confirming the presence of DH-ANA-a and E-ANA-a in the samples.

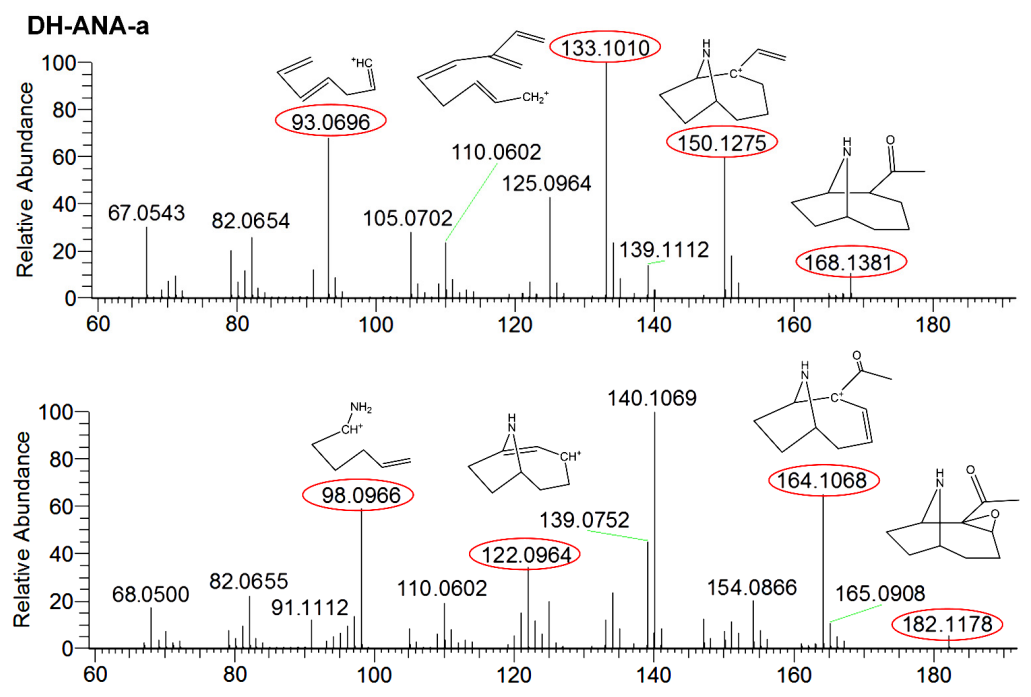

Figure 4. Fragmentation mass spectra of dihydroanatoxin-a (DH-ANA-a) with targeted product ions $m / z 168>93,133$, and 150 and epoxyanatoxin-a (E-ANA-a) with targeted product ions $m / z 182>98$, 122 , and 164 .

\subsection{Risk Assessment}

Various TDI guidelines have been proposed by many institutions for the intake of cyanotoxins in order to prevent toxic effects. The most recognized value was established by the WHO in the form of a TDI guideline of $0.04 \mu \mathrm{g} \cdot \mathrm{kg}^{-1}$ body weight for MCs. This value corresponds to an intake of $2.4 \mu \mathrm{g}$ of MCs per day for an adult weighing $60 \mathrm{~kg}$ [20]. So far, the WHO has not established guidelines for cyanotoxins other than MCs. The Oregon Health Authority (OHA) Public Health Division have established guidelines for additional toxins as part of the implementation of a monitoring program for the presence of cyanotoxins [41]. They developed TDI values for ANA-a $(6 \mu \mathrm{g})$, CYN $(1.8 \mu \mathrm{g})$, MCs $(3 \mu \mathrm{g})$, and STX (3 $\mu \mathrm{g})$. Our results indicate that the consumption of these 'health products' might be associated with health risks because of the presence of cyanotoxins in several CB products. Table 2 presents the results on the quantity of cyanotoxins ingested according to TDI, when applicable, for each brand. Out of the 18 brands, 4 contained cyanotoxins at levels exceeding TDI values. According to our results, these brands showed amounts of MCs exceeding the recommended TDI for adults (exceeding TDI by up to $683 \%$ for total MCs). 
Table 2. Cyanotoxins daily intake from CB dietary supplements samples ( $\mu \mathrm{g})$, and comparison with guidelines. Values in brackets represent the detected cyanotoxins as percentages of the WHO adult TDI guideline for MCs and the OHA Public Health Division for ANA-a, assuming the consumption of the maximum dosage and a body weight of $60 \mathrm{~kg}$.

\begin{tabular}{|c|c|c|c|c|c|c|c|c|c|c|c|c|c|c|c|}
\hline No. & MCs tot ${ }^{a, b}$ & ANA-a ${ }^{a}$ & ANA-a & DH-ANA-a ${ }^{c}$ & E-ANA-a ${ }^{c}$ & MC-RR & MC-YR & MC-LR & MC-LA & MC-LY & MC-LW & MC-LF & CYN & STX & BMAA \\
\hline 1 & ND & ND & ND & ND & ND & ND & ND & ND & ND & ND & ND & ND & ND & ND & ND \\
\hline 2 & ND & ND & ND & ND & ND & ND & ND & ND & ND & ND & ND & ND & ND & ND & ND \\
\hline 3 & ND & ND & ND & ND & ND & ND & ND & ND & ND & ND & ND & ND & ND & ND & ND \\
\hline 4 & ND & ND & ND & ND & ND & ND & ND & ND & ND & ND & ND & ND & ND & ND & ND \\
\hline 5 & ND & ND & ND & ND & 7.2 & ND & ND & ND & ND & ND & ND & ND & ND & ND & ND \\
\hline 6 & ND & ND & ND & ND & ND & ND & ND & ND & ND & ND & ND & ND & ND & ND & ND \\
\hline 7 & ND & ND & ND & ND & ND & ND & ND & ND & ND & ND & ND & ND & ND & ND & ND \\
\hline 8 & $0.25(10)$ & ND & ND & 0.41 & ND & ND & ND & ND & $0.3(13)$ & ND & ND & ND & ND & ND & ND \\
\hline 9 & ND & ND & ND & ND & ND & ND & ND & ND & ND & ND & ND & ND & ND & ND & ND \\
\hline 10 & ND & ND & ND & ND & ND & ND & ND & ND & ND & ND & ND & ND & ND & ND & ND \\
\hline 11 & $2.5(104)$ & ND & ND & ND & 8.1 & ND & $1.6(67)$ & $0.06(3)$ & $0.08(3)$ & ND & ND & ND & ND & ND & ND \\
\hline 12 & ND & ND & ND & ND & ND & ND & ND & ND & ND & ND & ND & ND & ND & ND & ND \\
\hline 13 & $0.6(25)$ & ND & ND & ND & ND & ND & ND & $0.03(1)$ & ND & ND & ND & ND & ND & ND & ND \\
\hline 14 & ND & ND & ND & ND & ND & ND & ND & ND & ND & ND & ND & ND & ND & ND & ND \\
\hline 15 & $16.4(683)$ & ND & $0.30(5)$ & 2.2 & 1.8 & 0.8 & ND & $8.6(358)$ & $2.2(92)$ & $0.04(17)$ & ND & ND & ND & ND & 0.08 \\
\hline 16 & $4.5(188)$ & ND & ND & ND & 0.28 & ND & ND & $3.6(150)$ & $1.2(50)$ & ND & ND & ND & ND & ND & ND \\
\hline 17 & $3.3(138)$ & $0.35(6)$ & $0.32(5)$ & 5.8 & ND & ND & $0.18(8)$ & $0.04(17)$ & $2.6(108)$ & ND & ND & ND & ND & ND & 0.44 \\
\hline 18 & $0.8(33)$ & ND & ND & ND & ND & ND & ND & $0.52(22)$ & ND & ND & ND & ND & ND & ND & ND \\
\hline
\end{tabular}

ND-Not detected. a Analysis using LDTD-APCI-HRMS detection. ${ }^{b}$ Total microcystins determined via MMPB reported as total MCs equivalent. ${ }^{\mathrm{c}}$ Concentrations are expressed as ANA-a equivalents. ${ }^{\mathrm{d}}$ Total microcystins determined via the summation of individual microcystins measured. 
The TDI values are for adults weighing $60 \mathrm{~kg}$ and therefore should be reduced for children. For example, the intake for a child weighing $30 \mathrm{~kg}$ (average for a 10-year-old) should not exceed half of the TDI values established for an adult. In addition to the four brands exceeding the TDI for total MCs for adults, another brand had a total MCs value of $0.8 \mu \mathrm{g}$, which is equivalent to the TDI for child weighing $20 \mathrm{~kg}$ (this product that did not warn against use for children). In our study, a third of the products analyzed had warnings against consumption by children (Table 3). Yet, CB supplementation has been suggested as an alternative (natural) therapy for children with attention deficit/hyperactivity disorder (ADHD) [48]. Some of these products have also been presented as providing health benefits to pregnant women [49].

Table 3. Information and specifics from cyanobacterial (CB) dietary supplements.

\begin{tabular}{|c|c|c|c|c|c|}
\hline No. & Content & $\begin{array}{l}\text { Place of Harvest/ } \\
\text { Purchased From }\end{array}$ & Exp. Date & $\begin{array}{c}\text { Recommended } \\
\text { Maximum Dosage/Day }\end{array}$ & Specifics \\
\hline 1 & Spirulina & Pacific/Store & $01 / 2006$ & $4000 \mathrm{mg}$ & - \\
\hline 3 & Spirulina & Hawaii/Store & $06 / 2006$ & $2000 \mathrm{mg}$ & - \\
\hline 4 & Spirulina & NA/Store & $02 / 2007$ & $2000 \mathrm{mg}$ & - \\
\hline 5 & Spirulina & NA/Store & $08 / 2007$ & $4500 \mathrm{mg}$ & Not recommended for children \\
\hline 8 & Spirulina & Hawaii/Store & $06 / 2008$ & $1200 \mathrm{mg}$ & - \\
\hline 9 & Spirulina & Hawaii/Store & $05 / 2009$ & $1200 \mathrm{mg}$ & - \\
\hline 10 & Spirulina & NA/Store & 06/2009 & $3040 \mathrm{mg}$ & Not recommended for children \\
\hline 11 & Spirulina & NA/Store & $07 / 2015$ & $3000 \mathrm{mg}$ & - \\
\hline 12 & Spirulina & NA/Internet & $05 / 2015$ & $3000 \mathrm{mg}$ & - \\
\hline 17 & A. flos-aquae & Klamath Lake/Internet & $06 / 2015$ & $800 \mathrm{mg}$ & - \\
\hline 18 & A. flos-aquae & Klamath Lake/Internet & 06/2015 & $1000 \mathrm{mg}$ & - \\
\hline
\end{tabular}

NA-Not available.

In addition, BMAA was found in two brands, although at low concentrations. The lack of toxicological data and guidelines does not allow the determination of the risk associated to chronic exposure of this compound. However, BMAA has been associated with neurodegenerative diseases [45,46], and it would seem appropriate to establish a preventive monitoring of this toxin including in CB dietary supplements. Furthermore, Andersson, M. et al. [50] have recently shown the possibility that mothers' milk could be a source of exposure for BMAA in human infants. This would be due to a low metabolic (or even non-metabolic) elimination of BMAA in addition to its transportation as a free amino acid to rat milk and suckling pups. Breastfed infants are therefore put at risk, considering that not a majority of brands contraindicate their products for breastfeeding women. Finally, ANA-a or its transformation compounds, DH-ANA-a and E-ANA-a, were found in six different samples. This suggests the presence of alkaloid cyanotoxins producers in the $\mathrm{CB}$ cultures, both in Spirulina and A. flos-aquae harvests. The level of risk appears low in our study since the estimated intake in the two samples where it was detected was much lower than the TDI. However, our sample size was limited, thus other products available commercially might contain larger levels of these cyanotoxins.

Published reports raise concerns for risks of intoxication and liver injuries caused by a chronic consumption of CB dietary supplements [51,52]. Although subchronic cyanotoxin poisoning can lead to acute symptoms, the ingested doses must be at least 10-fold higher than the TDI guidelines [53]. Similarly, some cases of acute poisoning from MCs were previously documented, as well as exposition causing mild intoxication cases [54,55]. Although acute poisoning can lead to symptoms ranging from temporary gastrointestinal disorders to immediate liver failure, long term intoxication is known to increase the risk of liver cancer [56]. Indeed, some cyanotoxins have the propriety to bioaccumulate, especially MCs. These are known to covalently bind in liver tissues through protein phosphatase 
inhibition, inducing hepatic failure and tumor promotion [56,57]. This suggests the potential risk of a chronic consumption of CB dietary supplements contaminated by cyanotoxins.

In this study, we were able to screen many cyanotoxins to assess their toxic potential. Our results showed that some dietary products could be harmful upon long term consumption due to the undesirable presence of cyanotoxins. They are widely available, and labeled as safe products, and even beneficial for health. The presence of unwanted and harmful toxins shows the need for a more thorough monitoring of such products to evaluate the risks assessments and public health implications associated with the sale of such uncontrolled natural products. Finally, most guidelines for maximum intake of $\mathrm{CB}$ are established for a lifetime-based consumption. However, the United States Environmental Protection Agency recently proposed a 10-day health advisory for bottle-fed infants $\left(0.3 \mu \mathrm{g} \cdot \mathrm{L}^{-1}\right)$ and children of pre-school age $\left(1.6 \mu \mathrm{g} \cdot \mathrm{L}^{-1}\right)$ on the presence of MCs in drinking water [58]. This new advisory indicates the increasing concern of public health authorities for the risks associated with exposure to these toxins.

\section{Conclusions}

CB dietary supplements are marketed internationally, easily available, and advertised as beneficial for health. However, these products are sold with limited quality control, which could lead to potential toxic risks related to the contamination by cyanotoxins. We investigated the presence of several cyanotoxins in 18 brands of CB dietary supplements containing Spirulina and Aphanizomenon flos-aquae to assess the potential risks of chronic consumption from these products. We targeted total microcystins via the MMPB moiety, seven individual MCs, ANA-a, two of its transformation products, DH-ANA-a and E-ANA-a, cylindrospermopsin, saxitoxin and BMAA. These cyanotoxins were monitored using different analytical approaches including LDTD-APCI-HRMS, UHPLC-HESI-HRMS, and chemical derivatization in order to obtain a broad assessment of the presence of cyanotoxins. Results showed that 8 brands out of 18 contained some levels of cyanotoxins both in Spirulina and A. flos-aquae supplements. From these brands, four were contaminated with microcystins at levels exceeding the TDI values established by the WHO and the Oregon Health Division. Moreover, ANA-a and its transformation products were found in six brands which suggests the presence of alkaloid cyanotoxins producers species in CB cultures. Finally, low amounts of BMAA were found in two A. flos-aquae samples, supporting earlier reports that this toxin can appear in such dietary supplements $[21,26]$. This should be of concern for public health since dietary exposure to BMAA is suspected to be a potent neurotoxin. Finally, we do not want to emphasize the health risks associated with the specific supplement brands that we have analyzed. We rather pointed out that our data show the importance of better monitoring by the appropriate authorities of all algal-based food supplements and eventually prompt the adoption of health-based guidelines on the maximum intake to ensure the safety of these products.

\section{Materials and Methods}

\subsection{Chemicals, Reagents, and Stock Solutions}

Detailed information on chemical standards, reagents, and solutions used in sample treatment, sample derivation and instrumental analysis are provided in the Supplementary Material (SI1).

\subsection{Algal Dietary Supplement Samples}

The samples of CB food supplements containing Spirulina and A. flos-aquae were obtained from several brands and different sources at different periods of time (Table 3). Some were purchased from commercial suppliers at different locations and others were purchased via the Internet. The cyanobacteria composition varied among samples and they included tablets, capsules, and powder. The CB dietary supplements were ground individually with a coffee grinder and $0.3 \mathrm{~g}$ was weighed from each powdered sample for subsequent extraction steps. 


\subsection{Sample Treatment Steps}

\subsubsection{MMPB via LDTD-APCI-HRMS}

For the analysis of total MCs via the MMPB moiety, the weighed samples were mixed in amber glass vials with $5 \mathrm{~mL}$ of the oxidation solution which consisted of $\mathrm{KMnO}_{4}(50 \mathrm{mM}), \mathrm{NaIO}_{4}(50 \mathrm{mM})$, and $\mathrm{K}_{2} \mathrm{CO}_{3}$ for a $\mathrm{pH}$ adjustment to 9 [28,29]. The oxidation duration was $2 \mathrm{~h}$ at room temperature and the reaction was quenched using a saturated solution of sodium bisulfite until the purple color in solution became colorless. The samples were acidified at $\mathrm{pH} \sim 2$ using a solution of $10 \%$ sulfuric acid. Afterwards, these were filtered with $0.22 \mu \mathrm{m}$ nylon membrane filters (Sterlitech Corporation, Kent, WA, USA). A solid phase extraction (SPE) step was employed for sample clean-up [28]. A styrene-divinylbenzene sorbent (Strata SDB-L) was used as the SPE cartridge from Phenomenex (Torrance, CA, USA) with $500 \mathrm{mg}$ bed mass and a volume of $6 \mathrm{~mL}$. A 12-position manifold from Phenomenex (Torrance, CA, USA) was used for the procedure. The SPE cartridges were conditioned with $5 \mathrm{~mL}$ of methanol $(\mathrm{MeOH})$ followed by $5 \mathrm{~mL}$ of acidified water with $0.1 \%$ formic acid. The samples were loaded on the cartridge columns by gravity. The cartridges were then washed twice by adding $5 \mathrm{~mL}$ of water with $0.1 \%$ formic acid and containing $10 \% \mathrm{MeOH}(v / v)$. The elution was performed using $5 \mathrm{~mL}$ of $\mathrm{MeOH}$ and the solvent was recovered into glass conical-bottom centrifuge tubes. The eluates were completely dried under a gentle stream of nitrogen at room temperature using a nine-port Reacti-Vap Pierce unit (Rockford, IL, USA). The dried fractions were then reconstituted in $500 \mu \mathrm{L}$ of acetonitrile (ACN) and finally submitted to the LDTD-APCI-HRMS detection.

\subsubsection{ANA-a via LDTD-HRMS and MCs-ANA-a via UHPLC-HESI-HRMS}

For the analysis of ANA-a via the LDTD-APCI-HRMS method and of MCs and ANA-a via the UHPLC-HESI-HRMS system, the weighed samples were mixed with $5 \mathrm{~mL}$ of acidified $\mathrm{MeOH}$ (formic acid, $\mathrm{pH} 2$ ) in polyethylene conical-bottom centrifuge tubes [27,31]. The samples were homogenized for $10 \mathrm{~min}$ using ultrasonication and then they were submitted to centrifugation at $3500 \mathrm{rpm}$ for $10 \mathrm{~min}$. The supernatant was filtered using $0.22 \mu \mathrm{m}$ nylon membrane filters and was transferred to a $15 \mathrm{~mL}$ conical-bottom glass centrifuge tube. Another $3 \mathrm{~mL}$ of acidified $\mathrm{MeOH}$ was added to the sample residues which were vortexed, centrifuged, and the supernatant was filtered and combined with the first suspension. The solvent was dried under a gentle stream of nitrogen at room temperature. For the analysis of ANA-a using the LDTD-APCI-HRMS, according to previous study, samples were reconstituted with $500 \mu \mathrm{L}$ of a solution of $\mathrm{H}_{2} \mathrm{O}: \mathrm{MeOH}(50: 50 v / v)$ acidified with formic acid at $\mathrm{pH} \sim 2$ and then they were directly submitted to analysis. For the analysis of MCs and ANA-a using the UHPLC-HESI-HRMS method, samples were reconstituted with $500 \mu \mathrm{L}$ of acidified water with $0.1 \%$ formic acid and submitted for analysis.

\subsubsection{BMAA, CYN, and STX via UHPLC-HESI-HRMS}

For the analysis of CYN, STX, and BMAA, the weighed samples were mixed in polypropylene conical-bottom centrifuge tubes with $5 \mathrm{~mL}$ of acidified water with citric acid ( $\mathrm{pH} \sim 4$ ) and were submitted to centrifugation at $3500 \mathrm{rpm}$ for $10 \mathrm{~min}$ [33]. Thereafter, the supernatants were filtered using $0.22 \mu \mathrm{m}$ nitrocellulose membrane filters (Millipore, Billerica, MA, USA) and then transferred into $15 \mathrm{~mL}$ polypropylene conical-bottom centrifuge tubes. Another $5 \mathrm{~mL}$ of acidified water was added to the sample residues to then be vortexed and centrifuged. The supernatant was filtered and combined with the first suspension. The combined solutions were submitted to a SPE clean-up step using a strong cation-exchange polymeric sorbent Strata- $\mathrm{X}-\mathrm{C}$ cartridge (Phenomenex, Torrance, CA, USA) with $200 \mathrm{mg}$ bed mass and a volume of $6 \mathrm{~mL}$. The conditioning step was done with $5 \mathrm{~mL}$ of methanol $(\mathrm{MeOH})$ followed by $5 \mathrm{~mL}$ of acidified water with citric acid $(\mathrm{pH} \sim 4)$. The acidified samples were then loaded on the cartridge columns by gravity. The cartridges were washed with $5 \mathrm{~mL}$ of acidified water $(\mathrm{pH} 4)$ containing $15 \% \mathrm{MeOH}(v / v)$. Elution was performed with $5 \mathrm{~mL}$ of $\mathrm{MeOH}$ containing 3\% $\mathrm{NH}_{4} \mathrm{OH}$ into conical-bottom polypropylene centrifuge tubes. The eluates were 
completely dried under a gentle stream of nitrogen at room temperature. The dried fractions were then reconstituted with the DNS reactive solution consisting of $250 \mu \mathrm{L}$ of a Borax buffer $(0.2 \mathrm{M}, \mathrm{pH} 9.5)$ and $250 \mu \mathrm{L}$ of DNS in acetone $\left(1 \mathrm{mg} \cdot \mathrm{mL}^{-1}\right)$. The tubes were vortexed and placed in an Innova 4230 incubator shaker from New Brunswick Scientific (Edison, NJ, USA) at $60{ }^{\circ} \mathrm{C}$ for $10 \mathrm{~min}$ with agitation at $150 \mathrm{rpm}$. The samples were finally cooled at room temperature and were directly submitted to the UHPLC-HESI-HRMS analysis.

\subsection{Analytical Detection}

\subsubsection{LDTD Conditions}

The analyte desorption was achieved with a T-960 LDTD-APCI ionization interface model and the instrument was controlled by LazSoft 4.0 software (Phytronix Technologies, Québec, QC, Canada) integrated with the Xcalibur 2.3 Software (Thermo Fisher Scientific, Waltham, MA, USA). Details of the LDTD apparatus were described in previous work [29,59-64]. An aliquot of $2 \mu \mathrm{L}$ of the MMPB extract and an aliquot of $4 \mu \mathrm{L}$ of the ANA-a extract were individually spotted into a LazWell 96-well sample metal plate. After complete solvent drying at $40{ }^{\circ} \mathrm{C}$ for $5 \mathrm{~min}$, the back of the sample well was heated by an infrared laser ( $980 \mathrm{~nm}, 20 \mathrm{~W}$, continuous) in the LDTD instrument. The sample was desorbed and thereafter, a carrier gas flow of $2 \mathrm{~L} \cdot \mathrm{min}^{-1}$ was set at a temperature of $50{ }^{\circ} \mathrm{C}$ to avoid temperature variation and to transfer the gas phase molecules to APCI ionization followed by the HRMS detection. Finally, the optimal laser power was set at $40 \%$ and laser pattern was optimized to the following settings for both analytical methods: $2 \mathrm{~s}$ at $0 \%, 2 \mathrm{~s}$ ramping from $0 \%$ to $40 \%, 1 \mathrm{~s}$ hold at $40 \%, 0.1 \mathrm{~s}$ from $40 \%$ to $0 \%$ and $2 \mathrm{~s}$ hold at $0 \%$, with a total desorption time of $7 \mathrm{~s}$ per sample. The APCI ionization was set in negative mode for MCs and in positive mode for ANA-a and was set with these parameters: ion sweep gas 0.3 , sheath gas, auxiliary gas, and skimmer offset are set to 0 (all arbitrary values), vaporizer temperature $0^{\circ} \mathrm{C}$, and capillary temperature $350{ }^{\circ} \mathrm{C}$.

\subsubsection{UHPLC Conditions}

The chromatographic separation was performed with a Thermo Scientific Dionex Ultimate 3000 Series RS pump coupled with a Thermo Scientific Dionex Ultimate 3000 Series TCC-3000RS column compartments and a Thermo Fisher Scientific Ultimate 3000 Series WPS-3000RS autosampler controlled by Chromeleon 7.2 Software (Thermo Fisher Scientific, Waltham, MA, USA and Dionex Softron $\mathrm{GMbH}$ Part of Thermo Fisher Scientific, Germering, Germany). The chromatographic column was a Hypersil GOLD ${ }^{\mathrm{TM}}$ C18 column $(100 \mathrm{~mm}, 2.1 \mathrm{~mm}, 1.9 \mu \mathrm{m}$ particles) preceded by a guard column (5 mm, $2.1 \mathrm{~mm}, 3 \mu \mathrm{m}$ particles) (Thermo Fisher Scientific, Waltham, MA, USA). Chromatographic settings are presented in Table 4 for both analytical methods and are based on published optimization parameters [31,33]. For the analysis of MCs and ANA-a, the injection volume was $25 \mu \mathrm{L}$ and flow rate was set at $525 \mu \mathrm{L} \cdot \mathrm{min}^{-1}$ with a constant temperature of $55^{\circ} \mathrm{C}$. Concerning the ionization, the final HESI parameters used to maximize signal intensity were as follows: capillary temperature, $350{ }^{\circ} \mathrm{C}$; vaporizer temperature, $450{ }^{\circ} \mathrm{C}$; sheath gas pressure, 35 arbitrary units; aux gas pressure (10 arbitrary units), ion sweep gas pressure, 0 arbitrary units; and spray voltage, +3200 V. For the analysis of CYN, STX and BMAA, the injection volume was $25 \mu \mathrm{L}$ and flow rate was set at $500 \mu \mathrm{L} \cdot \mathrm{min}^{-1}$ with a constant temperature of $40^{\circ} \mathrm{C}$. The HESI parameters were as follows: capillary temperature, $400^{\circ} \mathrm{C}$; vaporizer temperature, $350{ }^{\circ} \mathrm{C}$; sheath gas pressure, 30 arbitrary units; aux gas pressure, 10 arbitrary units, ion sweep gas pressure, 0 arbitrary units; and spray voltage, $+3000 \mathrm{~V}$. For the analysis of BMAA, as demonstrated in the publication which describes this methodology [33], BMAA is independently detected from two important isobaric isomers, 2,3-diaminobutyric acid and $\mathrm{N}$-(2-aminoethyl)-glycine through chromatographic separation and high resolution detection so that the results are not confounded. 
Table 4. Gradient parameters used for the analysis of cyanotoxins using UHPLC-HESI-HRMS, where A is HPLC water with $0.1 \%$ formic acid, B is acetonitrile with $0.1 \%$ formic acid, and C is methanol with $0.1 \%$ formic acid.

\begin{tabular}{ccccccc}
\hline & MCs and ANA-a & \multicolumn{3}{c}{ CYN, STX and BMAA } \\
\hline Time (min) & A (\%) & B (\%) & C (\%) & Time (min) & A (\%) & B (\%) \\
\hline 0.00 & 75 & 25 & 0 & 0.00 & 70 & 30 \\
0.35 & 45 & 55 & 0 & 2.00 & 10 & 90 \\
1.15 & 45 & 55 & 0 & 4.00 & 0 & 100 \\
1.16 & 55 & 0 & 45 & 6.00 & 0 & 100 \\
2.95 & 55 & 0 & 45 & 6.01 & 70 & 30 \\
4.51 & 5 & 0 & 95 & 10.00 & 70 & 30 \\
4.66 & 75 & 25 & 0 & & & \\
7.00 & 75 & 25 & 0 & & & \\
\hline
\end{tabular}

\subsubsection{HRMS Conditions}

The detection was performed using a Q-Exactive mass spectrometer controlled by the Xcalibur 2.3 Software (Thermo Fisher Scientific, Waltham, MA, USA). Instrument calibration in positive and negative modes was done every five days to avoid mass shifts in detection with a direct infusion of a LTQ Velos ESI positive and negative ion calibration solutions (Pierce Biotechnology Inc., Rockford, IL, USA). Targeted ion fragmentation ( $\left.\mathrm{t}-\mathrm{MS}^{2}\right)$ mode was used for quantification and the normalized collision energy (NCE) is presented in Table S3 along with the precursor and product masses of target analytes. The precursor ions are filtered by the quadrupole which operates at an isolation width of $0.4 \mathrm{amu}$. A resolving power of 17,500 FWHM at $m / z 200$ was used with an automatic gain control (AGC) target set at $1 \times 10^{5}$ ions for a maximum injection time of $50 \mathrm{~ms}$. For more technical details, please refer to these previous studies [27,65-67].

\subsection{Method Validation}

The data treatment was performed using the Xcalibur 2.3 Software (Thermo Fisher Scientific, Waltham, MA, USA). The mass window applied for the extraction of chromatograms was $5 \mathrm{ppm}$. The recovery values from the extraction methods and the matrix effects as well as the method validation parameters were evaluated using material consisting of Chlorella-based dietary supplement products. Chlorella is a unicellular plant which is not related to cyanobacteria, so it was chosen as matrix blank. Extraction recoveries were determined at two levels depending of the analytical method, see Table 1, using the mean peak area of target compounds spiked prior to extraction in Chlorella samples. The results were compared to spiked post-extraction samples and were reported as percentages of recovery. The matrix effects were evaluated with the mean peak area of target compounds in post extraction spiked Chlorella samples compared to post extraction spiked matrix-free $\left(\mathrm{dd}-\mathrm{H}_{2} \mathrm{O}\right)$ samples. They were evaluated at two concentration levels, see Table 1 , and were reported as percentages of signal recovery from matrix effects. All recovery values were evaluated using triplicate determinations. Five-point internal calibration curves were prepared in Chlorella samples submitted to extraction with concentration levels ranging from 0.03 to $20 \mu \mathrm{g} \cdot \mathrm{g}^{-1}$ depending on target compounds. For all analytical methods, the concentration of internal standards was selected at $2.5 \mu \mathrm{g} \cdot \mathrm{g}^{-1}$ for its capacity for signal correction (data not shown). The internal standards were added before extraction steps as follows: 4-phenylbutyric acid (4-PB) for the analysis of MMPB, phenylalanine- $\mathrm{D}_{5}\left(\mathrm{PHE}-\mathrm{D}_{5}\right)$ for the analysis of ANA-a, nodularin (NOD) for the analysis of MCs and ANA-a and diaminobutyric acid- $\mathrm{D}_{3}$ $\left(\mathrm{DAB}-\mathrm{D}_{3}\right)$ for the analysis of CYN, STX, and BMAA. Method detection limit (MDL) and method quantification limit (MQL) were determined as 3.3 and 10 times, respectively, the standard deviation of the y-intercept divided by the slope of the calibration curve in Chlorella samples. MDL values were confirmed experimentally by analyzing each compound at the statistically calculated concentrations. Accuracy, expressed as relative error (\%); and interday/intraday variations, expressed as the relative 
standard deviation (\%), were determined with two different concentration levels on the linearity range $\left(0.5\right.$ and $\left.10 \mu \mathrm{g} \cdot \mathrm{g}^{-1}, n=3\right)$ in Chlorella samples. Interday repeatability was estimated over three weeks.

Supplementary Materials: The following are available online at www.mdpi.com/2072-6651/9/3/76/s1, SI1: Chemicals, reagents, and stock solutions, Table S1: Recoveries from matrix effects of targeted cyanotoxins evaluated at two different concentrations levels $\left(\mu \mathrm{g} \cdot \mathrm{g}^{-1}\right)$ with standard deviation (STD, $\left.n=3\right)$., Table S2: Cyanotoxins detection in CB dietary supplements $\left(\mu \mathrm{g} \cdot \mathrm{g}^{-1}\right)$ with relative standard deviation (RSD-\%)., Table S3: Parameters of HRMS detection of target cyanotoxins and internal standards.

Acknowledgments: Genome Québec, Genome Canada, the Natural Sciences and Engineering Research Council of Canada (NSERC) and the Canadian Foundation for Innovation (equipment) are acknowledged for their financial support. We thank Thermo Fisher Scientific and Phytronix Technologies for their support. We also thank Sung Vo Duy for technical help and scientific support.

Author Contributions: A.R.-L. conceived, designed, and performed all experiments, analyzed the data and wrote the paper. M.S. contributed to the experiments and revised the paper critically. M.F.B. contributed to the paper and revised the paper critically. S.S. conceived and designed the experiments, contributed to the paper, and has given final approval of the version to be published.

Conflicts of Interest: The authors declare no conflict of interest.

\section{References}

1. Merel, S.; Walker, D.; Chicana, R.; Snyder, S.; Baures, E.; Thomas, O. State of knowledge and concerns on cyanobacterial blooms and cyanotoxins. Environ. Int. 2013, 59, 303-327. [CrossRef] [PubMed]

2. Paerl, H.W.; Otten, T.G. Harmful cyanobacterial blooms: Causes, consequences, and controls. Microb. Ecol. 2013, 65, 995-1010. [CrossRef] [PubMed]

3. Van Apeldoorn, M.E.; Van Egmond, H.P.; Speijers, G.J.; Bakker, G.J. Toxins of cyanobacteria. Mol. Nutr. Food. Res. 2007, 51, 7-60. [CrossRef] [PubMed]

4. Paerl, H.W.; Paul, V.J. Climate change: Links to global expansion of harmful cyanobacteria. Water Res. 2012, 46, 1349-1363. [CrossRef] [PubMed]

5. O'neil, J.; Davis, T.W.; Burford, M.A.; Gobler, C. The rise of harmful cyanobacteria blooms: The potential roles of eutrophication and climate change. Harmful Algae 2012, 14, 313-334. [CrossRef]

6. Oliver, R.L.; Hamilton, D.P.; Brookes, J.D.; Ganf, G.G. Physiology, blooms and prediction of planktonic cyanobacteria. In Ecology of Cyanobacteria II; Whitton, B.A., Ed.; Springer: Dordrecht, The Netherland, 2012; pp. 155-194.

7. Persson, P.B.; Zakrisson, A. Dietary supplements: Health from the ocean? Acta Physiol. 2015, 215. [CrossRef] [PubMed]

8. Ku, C.S.; Yang, Y.; Park, Y.; Lee, J. Health benefits of blue-green algae: Prevention of cardiovascular disease and nonalcoholic fatty liver disease. J. Med. Food 2013, 16, 103-111. [CrossRef] [PubMed]

9. Hoseini, S.; Khosravi-Darani, K.; Mozafari, M. Nutritional and medical applications of Spirulina microalgae. Mini Rev. Med. Chem. 2013, 13, 1231-1237. [CrossRef]

10. Carmichael, W.W.; Drapeau, C.; Anderson, D.M. Harvesting of Aphanizomenon flos-aquae ralfs ex born. \& flah. Var. Flos-aquae (cyanobacteria) from Klamath lake for human dietary use. J. Appl. Phycol. 2000, 12, 585-595.

11. Saker, M.L.; Welker, M.; Vasconcelos, V.M. Multiplex pcr for the detection of toxigenic cyanobacteria in dietary supplements produced for human consumption. Appl. Microbiol. Biotechnol. 2007, 73, 1136-1142. [CrossRef] [PubMed]

12. Vichi, S.; Lavorini, P.; Funari, E.; Scardala, S.; Testai, E. Contamination by Microcystis and microcystins of blue-green algae food supplements (bgas) on the italian market and possible risk for the exposed population. Food Chem. Toxicol. 2012, 50, 4493-4499. [CrossRef] [PubMed]

13. Rellán, S.; Osswald, J.; Saker, M.; Gago-Martinez, A.; Vasconcelos, V. First detection of anatoxin-a in human and animal dietary supplements containing cyanobacteria. Food Chem. Toxicol. 2009, 47, 2189-2195. [CrossRef] [PubMed]

14. Ballot, A.; Krienitz, L.; Kotut, K.; Wiegand, C.; Metcalf, J.S.; Codd, G.A.; Pflugmacher, S. Cyanobacteria and cyanobacterial toxins in three alkaline rift valley lakes of Kenya-lakes Bogoria, Nakuru and Elmenteita. J. Plankton Res. 2004, 26, 925-935. [CrossRef]

15. Petroczi, A.; Taylor, G.; Naughton, D. Mission impossible? Regulatory and enforcement issues to ensure safety of dietary supplements. Food Chem. Toxicol. 2011, 49, 393-402. [CrossRef] [PubMed] 
16. Dietrich, D.; Hoeger, S. Guidance values for microcystins in water and cyanobacterial supplement products (blue-green algal supplements): A reasonable or misguided approach? Toxicol. Appl. Pharm. 2005, 203, 273-289. [CrossRef] [PubMed]

17. Draisci, R.; Ferretti, E.; Palleschi, L.; Marchiafava, C. Identification of anatoxins in blue-green algae food supplements using liquid chromatography-tandem mass spectrometry. Food Addit. Contam. 2001, 18, 525-531. [CrossRef] [PubMed]

18. Lawrence, J.F.; Menard, C. Determination of microcystins in blue-green algae, fish and water using liquid chromatography with ultraviolet detection after sample clean-up employing immunoaffinity chromatography. J. Chromatogr. A 2001, 922, 111-117. [CrossRef]

19. Gilroy, D.J.; Kauffman, K.W.; Hall, R.A.; Huang, X.; Chu, F.S. Assessing potential health risks from microcystin toxins in blue-green algae dietary supplements. Environ. Health Perspect. 2000, 108, 435-439. [CrossRef] [PubMed]

20. World Health Organization. Guidelines for Drinking-Water Quality, 4th ed.; World Health Organization: Geneva, Switzerland, 2011; p. 541.

21. Cox, P.A.; Banack, S.A.; Murch, S.J.; Rasmussen, U.; Tien, G.; Bidigare, R.R.; Metcalf, J.S.; Morrison, L.F.; Codd, G.A.; Bergman, B. Diverse taxa of cyanobacteria produce $\beta$-n-methylamino-L-alanine, a neurotoxic amino acid. Proc. Natl. Acad. Sci. USA 2005, 102, 5074-5078. [CrossRef] [PubMed]

22. Rapala, J.; Sivonen, K.; Luukkainen, R.; Niemelä, S.I. Anatoxin-a concentration in anabaena and aphanizomenon under different environmental conditions and comparison of growth by toxic and non-toxic anabaena-strains-A laboratory study. J. Appl. Phycol. 1993, 5, 581-591. [CrossRef]

23. Sivonen, K.; Niemelä, S.; Niemi, R.; Lepistö, L.; Luoma, T.; Räsänen, L. Toxic cyanobacteria (blue-green algae) in finnish fresh and coastal waters. Hydrobiologia 1990, 190, 267-275. [CrossRef]

24. Scott, P.M.; Niedzwiadek, B.; Rawn, D.F.K.; Lau, B.P.Y. Liquid chromatographic determination of the cyanobacterial toxin $\beta-N$-methylamino-L-alanine in algae food supplements, freshwater fish, and bottled water. J. Food Prot. 2009, 72, 1769-1773. [CrossRef] [PubMed]

25. Glover, W.; Baker, T.C.; Murch, S.J. Determination of $\beta$ - $N$-methylamino-L-alanine, $N$-(2-aminoethyl) glycine, and 2, 4-diaminobutyric acid in food products containing cyanobacteria by ultra-performance liquid chromatography and tandem mass spectrometry: Single-laboratory validation. J. Aoac. Int. 2015, 98, 1559-1565. [CrossRef] [PubMed]

26. Dietrich, D.R.; Fischer, A.; Michel, C.; Hoeger, S.J. Toxin mixture in cyanobacterial blooms-A critical comparison of reality with current procedures employed in human health risk assessment. Adv. Exp. Med. Biol. 2008, 619, 885-912. [PubMed]

27. Roy-Lachapelle, A.; Solliec, M.; Sinotte, M.; Deblois, C.; Sauvé, S. High resolution/accurate mass (HRMS) detection of anatoxin-a in lake water using LDTD-APCI coupled to a Q-Exactive mass spectrometer. Talanta 2015, 132, 836-844. [CrossRef] [PubMed]

28. Roy-Lachapelle, A.; Solliec, M.; Sinotte, M.; Deblois, C.; Sauve, S. Total analysis of microcystins in fish tissue using laser thermal desorption-atmospheric pressure chemical ionization-high-resolution mass spectrometry (LDTD-APCI-HRMS). J. Agric. Food Chem. 2015, 63, 7440-7449. [CrossRef] [PubMed]

29. Roy-Lachapelle, A.; Fayad, P.B.; Sinotte, M.; Deblois, C.; Sauve, S. Total microcystins analysis in water using laser diode thermal desorption-atmospheric pressure chemical ionization-tandem mass spectrometry. Anal. Chim. Acta 2014, 820, 76-83. [CrossRef] [PubMed]

30. Rinehart, K.L.; Harada, K.; Namikoshi, M.; Chen, C.; Harvis, C.A.; Munro, M.H.G.; Blunt, J.W.; Mulligan, P.E.; Beasley, V.R.; Dahlem, A.M.; et al. Nodularin, microcystin, and the configuration of ADDA. J. Am. Chem. Soc. 1988, 110, 8557-8558. [CrossRef]

31. Fayad, P.B.; Roy-Lachapelle, A.; Duy, S.V.; Prévost, M.; Sauvé, S. On-line solid-phase extraction coupled to liquid chromatography tandem mass spectrometry for the analysis of cyanotoxins in algal blooms. Toxicon 2015, 108, 167-175. [CrossRef] [PubMed]

32. James, K.J.; Furey, A.; Sherlock, I.R.; Stack, M.A.; Twohig, M.; Caudwell, F.B.; Skulberg, O.M. Sensitive determination of anatoxin-a, homoanatoxin-a and their degradation products by liquid chromatography with fluorimetric detection. J. Chromatogr. A 1998, 798, 147-157. [CrossRef]

33. Roy-Lachapelle, A.; Solliec, M.; Sauve, S. Determination of BMAA and three alkaloid cyanotoxins in lake water using dansyl chloride derivatization and high-resolution mass spectrometry. Anal. Bioanal. Chem. 2015, 407, 5487-5501. [CrossRef] [PubMed] 
34. Diener, M.; Erler, K.; Hiller, S.; Christian, B.; Luckas, B. Determination of paralytic shellfish poisoning (PSP) toxins in dietary supplements by application of a new HPLC/FD method. Eur. Food Res. Technol. 2006, 224, 147-151. [CrossRef]

35. Liu, H.; Scott, P. Determination of the cyanobacterial toxin cylindrospermopsin in algal food supplements. Food Addit. Contam. 2011, 28, 786-790. [CrossRef] [PubMed]

36. McCarron, P.; Logan, A.C.; Giddings, S.D.; Quilliam, M.A. Analysis of $\beta-N$-methylamino-L-alanine (BMAA) in Spirulina-containing supplements by liquid chromatography-tandem mass spectrometry. Aquat. Biosyst. 2014, 10, 1-7. [CrossRef] [PubMed]

37. Suchy, P.; Berry, J. Detection of total microcystin in fish tissues based on Lemieux oxidation and recovery of 2-methyl-3-methoxy-4-phenylbutanoic acid (MMPB) by solid-phase microextraction gas chromatography-mass spectrometry (SPME-GC/MS). Int. J. Environ. Anal. Chem. 2012, 92, 1443-1456. [CrossRef] [PubMed]

38. Neffling, M.R.; Lance, E.; Meriluoto, J. Detection of free and covalently bound microcystins in animal tissues by liquid chromatography-tandem mass spectrometry. Environ. Pollut. 2010, 158, 948-952. [CrossRef] [PubMed]

39. Kaushik, R.; Balasubramanian, R. Methods and approaches used for detection of cyanotoxins in environmental samples: A review. Crit. Rev. Environ. Sci. Technol. 2013, 43, 1349-1383. [CrossRef]

40. Moreira, C.; Ramos, V.; Azevedo, J.; Vasconcelos, V. Methods to detect cyanobacteria and their toxins in the environment. Appl. Microbiol. Biot. 2014, 98, 8073-8082. [CrossRef] [PubMed]

41. Farrer, D.; Counter, M.; Hillwig, R.; Cude, C. Health-based cyanotoxin guideline values allow for cyanotoxin-based monitoring and efficient public health response to cyanobacterial blooms. Toxins 2015, 7, 457-477. [CrossRef] [PubMed]

42. Heussner, A.H.; Mazija, L.; Fastner, J.; Dietrich, D.R. Toxin content and cytotoxicity of algal dietary supplements. Toxicol. Appl. Pharmacol. 2012, 265, 263-271. [CrossRef] [PubMed]

43. Shimamatsu, H. Mass production of spirulina, an edible microalga. In Asian Pacific Phycology in the 21st Century: Prospects and Challenges; Springer: Berlin, Germany, 2004; pp. 39-44.

44. Costa, J.A.V.; de Morais, M.G.; Dalcanton, F.; Reichert, C.d.C.; Durante, A.J. Simultaneous cultivation of Spirulina platensis and the toxigenic cyanobacteria Microcystis aeruginosa. Z Naturforsch C 2006, 61, 105-110. [CrossRef] [PubMed]

45. Cox, P.A.; Banack, S.A.; Murch, S.J. Biomagnification of cyanobacterial neurotoxins and neurodegenerative disease among the chamorro people of Guam. Proc. Natl. Acad. Sci. USA 2003, 100, 13380-13383. [CrossRef] [PubMed]

46. Cox, P.A.; Davis, D.A.; Mash, D.C.; Metcalf, J.S.; Banack, S.A. Dietary exposure to an environmental toxin triggers neurofibrillary tangles and amyloid deposits in the brain. Proc. R. Soc. B 2016, 283. [CrossRef] [PubMed]

47. Sanchez, J.A.; Otero, P.; Alfonso, A.; Ramos, V.; Vasconcelos, V.; Aráoz, R.; Molgó, J.; Vieytes, M.R.; Botana, L.M. Detection of anatoxin-a and three analogs in Anabaena spp. Cultures: New fluorescence polarization assay and toxin profile by lc-ms/ms. Toxins 2014, 6, 402-415. [CrossRef] [PubMed]

48. Chan, E. The role of complementary and alternative medicine in attention-deficit hyperactivity disorder. J. Dev. Behav. Pediatr. 2002, 23, S37-S45. [CrossRef] [PubMed]

49. Kapoor, R.; Mehta, U. Supplementary effect of spirulina on hematological status of rats during pregnancy and lactation. Plant Foods Hum. Nutr. 1998, 52, 315-324. [CrossRef] [PubMed]

50. Andersson, M.; Karlsson, O.; Banack, S.A.; Brandt, I. Transfer of developmental neurotoxin $\beta-N$-methylamino-L-alanine (BMAA) via milk to nursed offspring: Studies by mass spectrometry and image analysis. Toxicol. Lett. 2016, 258, 108-114. [CrossRef] [PubMed]

51. Dietrich, D.; Ernst, B.; Day, B. Human consumer death and algal supplement consumption: A post mortem assessment of potential microcystin-intoxication via microcystin immunoistochemical (mcich) analyses. In Proceedings of the 7th International Conference on Toxic Cyanobacteria, Rio de Janeiro, Brazil, 5-10 August 2007; p. 132.

52. Iwasa, M.; Yamamoto, M.; Tanaka, Y.; Kaito, M.; Adachi, Y. Spirulina-associated hepatotoxicity. Am. J. Gastroenterol. 2002, 97, 3212-3213. [CrossRef] [PubMed]

53. Funari, E.; Testai, E. Human health risk assessment related to cyanotoxins exposure. CRC Crit. Rev. Toxicol. 2008, 38, 97-125. [CrossRef] [PubMed] 
54. Carmichael, W.W.; Azevedo, S.M.; An, J.S.; Molica, R.J.; Jochimsen, E.M.; Lau, S.; Rinehart, K.L.; Shaw, G.R.; Eaglesham, G.K. Human fatalities from cyanobacteria: Chemical and biological evidence for cyanotoxins. Environ. Health Perspect. 2001, 109, 663-668. [CrossRef] [PubMed]

55. Giannuzzi, L.; Sedan, D.; Echenique, R.; Andrinolo, D. An acute case of intoxication with cyanobacteria and cyanotoxins in recreational water in Salto Grande Dam, Argentina. Mar. Drugs 2011, 9, 2164-2175. [CrossRef] [PubMed]

56. Svirčev, Z.; Baltić, V.; Gantar, M.; Juković, M.; Stojanović, D.; Baltić, M. Molecular aspects of microcystin-induced hepatotoxicity and hepatocarcinogenesis. J. Environ. Sci. Health C 2010, 28, 39-59. [CrossRef] [PubMed]

57. Fujiki, H.; Suganuma, M. Carcinogenic aspects of protein phosphatase 1 and 2a inhibitors. In Marine Toxins as Research Tools; Fusetani, N., Kem, W., Eds.; Springer: Berlin/Heidelberg, Germany, 2009.

58. Lesley, V.; D'Anglada, J.S. Drinking Water Health Advisory for the Cyanobacterial Microcystin Toxins; USEPA: Washington, DC, USA, 2015.

59. Solliec, M.; Massé, D.; Sauvé, S. Analysis of trimethoprim, lincomycin, sulfadoxin and tylosin in swine manure using laser diode thermal desorption-atmospheric pressure chemical ionization-tandem mass spectrometry. Talanta 2014, 128, 23-30. [CrossRef] [PubMed]

60. Lemoine, P.; Roy-Lachapelle, A.; Prévost, M.; Tremblay, P.; Solliec, M.; Sauvé, S. Ultra-fast analysis of anatoxin-a using laser diode thermal desorption-atmospheric pressure chemical ionization-tandem mass spectrometry: Validation and resolution from phenylalanine. Toxicon 2013, 61, 165-174. [CrossRef] [PubMed]

61. Boisvert, M.; Fayad, P.B.; Sauvé, S. Development of a new multi-residue laser diode thermal desorption atmospheric pressure chemical ionization tandem mass spectrometry method for the detection and quantification of pesticides and pharmaceuticals in wastewater samples. Anal. Chim. Acta 2012, 754, 75-82. [CrossRef] [PubMed]

62. Viglino, L.; Prévost, M.; Sauvé, S. High throughput analysis of solid-bound endocrine disruptors by LDTD-APCI-MS/MS. J. Environ. Monit. 2011, 13, 583-590. [CrossRef] [PubMed]

63. Segura, P.A.; Tremblay, P.; Picard, P.; Gagnon, C.; Sauvé, S. High-throughput quantitation of seven sulfonamide residues in dairy milk using laser diode thermal desorption-negative mode atmospheric pressure chemical ionization tandem mass spectrometry. J. Agric. Food Chem. 2010, 58, 1442-1446. [CrossRef] [PubMed]

64. Fayad, P.B.; Prévost, M.; Sauvé, S. Laser diode thermal desorption/atmospheric pressure chemical ionization tandem mass spectrometry analysis of selected steroid hormones in wastewater: Method optimization and application. Anal. Chem. 2010, 82, 639-645. [CrossRef] [PubMed]

65. Solliec, M.; Roy-Lachapelle, A.; Sauve, S. Quantitative performance of liquid chromatography coupled to q-exactive high resolution mass spectrometry (HRMS) for the analysis of tetracyclines in a complex matrix. Anal. Chim. Acta 2015, 853, 415-424. [CrossRef] [PubMed]

66. Fedorova, G.; Randak, T.; Lindberg, R.H.; Grabic, R. Comparison of the quantitative performance of a q-exactive high-resolution mass spectrometer with that of a triple quadrupole tandem mass spectrometer for the analysis of illicit drugs in wastewater. Rapid. Commun. Mass Spectron. 2013, 27, 1751-1762. [CrossRef] [PubMed]

67. Zhang, Y.; Hao, Z.; Kellmann, M.; Huhmer, A. HR/AM targeted peptide quantitation on a Q Exactive MS: A unique combination of high selectivity, sensitivity, and throughput. Thermo Fish. Sci. Appl. Note 2012, 554, $1-12$.

(C) 2017 by the authors. Licensee MDPI, Basel, Switzerland. This article is an open access article distributed under the terms and conditions of the Creative Commons Attribution (CC BY) license (http:/ / creativecommons.org/licenses/by/4.0/). 